\title{
Edi Test Validation for Detection of Delay in the Psychomotor Development of Children Under 5 Years Old
}

\author{
Alicia Santa Cortes González ${ }^{1 *}$, Mauricio Alejandro Escobar Celis ${ }^{2}$, Rosalba Mendoza Rivera ${ }^{3}$, José Artemio Cruz \\ López $^{4}$ and Héctor Hugo López Medina ${ }^{5}$ \\ ${ }^{1}$ Universidad Veracruzana, Pediatric Service General Hospital of Zone No. 11 Mexican Institute of Social Security of Xalapa Veracruz, Mexico. \\ ${ }^{2}$ Popular Autonomous University of the State of Puebla, Resident Physician of Family Medicine, family medicine unit no. 66 Mexican Institute \\ of Social Security Xalapa Veracruz Mexico. \\ ${ }^{3}$ National Autonomous University of Mexico, Family Medicine Unit no. 66 Mexican Institute of Social Security Xalapa Veracruz Mexico. \\ ${ }^{4} J u s t o$ Sierra University of the Federal District, Head of epidemiology General Hospital No. 11 Mexican Institute of Social Security Xalapa \\ Veracruz Mexico.
}

${ }^{5}$ Universidad Veracruzana, Family Medicine Unit \# 19. Mexican Institute of Social Security Banderilla Veracruz., Mexico.

*Corresponding author: Dr. Alicia Santa Cortés González, HGZ Pediatric Service No. 11 Mexican Social Security Institute Centro, Xalapa Veracruz, Mexico.

\begin{abstract}
Summary
Introduction: The psychomotor development evaluation (DSM) is an essential component in health supervision mainly in children under 5 years. The objective of this study is to favor the investigation of retardation in psychomotor development and allow that it is possible to intervene early and in a timely manner. Patients and methods: A descriptive, prospective, cross-sectional, observational study was carried out in the outpatient clinic of the family medicine unit Number 66 of the Mexican Social Security Institute, Xalapa Veracruz. During a year in the right-wing population of children from 1 month to 59 months of age, patients with neurological disease were excluded, a sample of 388 children was obtained and evaluated with the Child Development Assessment (EDI) test in three ABC groups. Results in group A from 1 to 2 months and group B from 2 to 11 months of age, no delay in psychomotor development was found, in group C from 12 to 59 months 4 children had developmental delay being $1.3 \%$ of the population studied, presenting alterations in the fine motor area with $0.3 \%$, the language area $1.5 \%$ and the social area $1.5 \%$ being this group the most representative. Conclusions: the EDI test was shown to be useful for the detection of psychomotor development delay in children under 5 years of age, mainly with a history of prematurity and low birth weight.
\end{abstract}

Keywords: Psychomotor Development (DSM); Evaluation of Child Development (EDI) Motor Delay; Total Development Quotient (CTD)

\section{Introduction}

Child development is a process where the level of maturation reached by a child within his age group can be recognized and quantified [1]. The American Academy of Pediatrics suggests continuous monitoring and development monitoring, taking into account biological and environmental risk factors, for this purpose it recommends the use of standardized tests at 9,18 and 30 months of age [2]. The psychomotor development evaluation (DSM) is an essential component in health supervision mainly in children under 5 years [3]. The Child Development Assessment Instrument (EDI) was designed in 2007 at Mc Master University, Canada. It focuses on children from 1 to 59 months who measures in different age groups the different aspects of development [4]. There are five main skill groups that make up the expected events according to a certain age [5]:

a) Thick motor: the use of large groups of muscles to sit, stand, walk, run, to maintain balance and change positions.

b) Fine motor skills: the use of hands and fingers to eat, draw, dress, play, write and do many other things. 
c) Language: speaking, using body language and gestures, communication and understanding of what others say.

d) Cognitive: thinking skills such as learning, understanding, problem solving, reasoning and remembering.

e) Social: interaction with others, having relationships with family, friends and teachers, cooperating and responding to the feelings of others [6]. This test provides us with warning and alarm signals, it has been standardized so that children under 5 years of age are classified with a traffic light in red, yellow and green that translate a probable delay, a risk of lag in development and development normal respectively. The objective of this study is to favor the investigation of developmental delay and allow that the doctor can intervene early and in a timely manner by sending him to pediatrics and rehabilitation.

\section{Patients and Methods}

A descriptive, prospective, cross-sectional, observational study was carried out in the outpatient clinic of the family medicine unit Number 66 of the Mexican Social Security Institute, Xalapa Veracruz. For one year, all infants and preschoolers between 1 and 59 months of age assigned to this unit were recruited sequentially, in a non-random sampling for convenience until the sample size was completed. Patients with neurological pathology were excluded. It was decided to obtain a sample size of 388 patients from a population of 11,000 children under 5 years attached to this unit. For the sample calculation the formula was used considering different correlation coefficients to estimate, with a $95 \%$ confidence level,

$$
\text { Sample size }=\frac{\frac{z^{2} \times p(1-p)}{e^{2}}}{1+\left(\frac{z^{2} \times p(1-p)}{e^{2} N}\right)}
$$

$\mathrm{N}=$ population size $\bullet \mathrm{e}=$ margin of error (percentage expressed with decimals) $\bullet \mathrm{z}=\mathrm{z}$ score

To identify the level of child development with the EDI tool, the traffic light criteria were applied (normal development green, yellow lag in development and red risk for developmental delay) and by age group with approximate duration of 20 to $40 \mathrm{~min}$ per test. The information corresponding to sociodemographic, family, and perinatal history characteristics were obtained through a direct interview with the parents or guardians recorded in a data collection sheet designed for this purpose. The project was approved by the local committee and registered with SIRELCIS with the number R-2019-3007-012.

\section{Statistic Analysis}

A univariate descriptive analysis was performed, and measures of central tendency, simple frequency and dispersion were calculated. According to the distribution of the variables under study; average, standard deviation and fashion were taken.

\section{Results}

The average age for the sample was 29.33 months, with a standard deviation of 15.79 months; the age range had upper and lower limits 1 and 59 months, respectively, which ensures the homogeneity of the sample with respect to age at study entry. The average gestation weeks at birth was 39.47 weeks, with a standard deviation of 1.07 weeks; The gestational age range was 33 and 42 weeks by upper and lower limits at birth.Table1 With regard to height at birth and weight at birth, 43.4 centimeters and 3.36 kilograms were obtained on average, with a standard deviation of 3.58 centimeters and 327 grams, the majority of patients reached full term in their gestational age. The sociodemographic variables found were that $57.1 \%$ were male, in the caregiver's variable, the mother was the main guardian in $88.4 \%$ of the cases. $70.4 \%$ had a bachelor's degree by last degree of studie. According to the different age groups presented in the EDI manual, the gross motor, fine motor, language, social and cognitive fields were addressed, in Group A (1 to 2 months of age) 1 subject was surveyed, not finding alterations in Group B (2 to 11 months old) 38 subjects were surveyed, there were no alterations and in Group C (12 to 59 months old), 345 were surveyed and it was observed that 4 patients equivalent to $1.3 \%$ of the population was delayed in its development being significant, with a history of having presented at birth between 33 and $36 \mathrm{sdg}$, with a weight of 2000 to $2450 \mathrm{~kg}$ was found alteration in the Fine Motor field in $0.3 \%$ alteration in the area of Language in $1.5 \%$, as well as alteration in the Social area in $1.5 \%$ of minors.(Figure1).

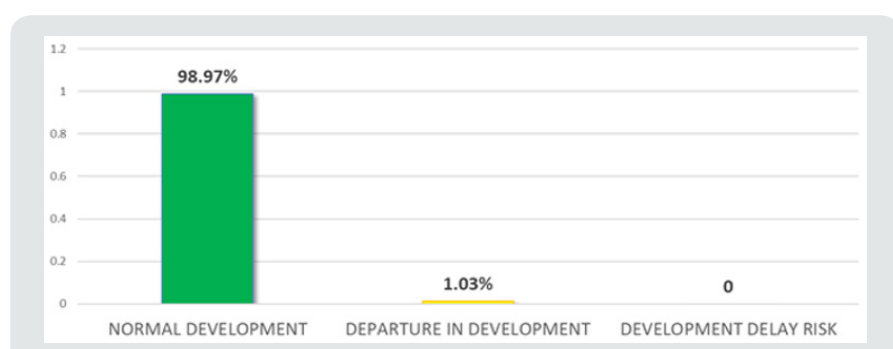

Figure 1: Child development in children under 5 years old of UMF 66.

Table 1: Perinatal Background of Children Under 5 Years Added to UMF 66.

\begin{tabular}{|c|c|c|c|c|}
\hline & Mínimum & Máximum & Average & Def.typ \\
\hline $\begin{array}{c}\text { Gestation } \\
\text { weeks }\end{array}$ & 33 & 42 & 39.47 & 1.070 \\
\hline Size at birth & 31.0 & 54.0 & 43.430 & 3.5766 \\
\hline Birth weight & 2.200 & 4.510 & 3.36247 & .327695 \\
\hline Apgar & 7 & 9 & 8.35052 & 0,71855 \\
\hline & & & & $\mathrm{n}=388$ \\
\hline
\end{tabular}

\section{Discussion}

The EDI was established in the early 2000s and was adopted as a monitoring tool in most of the provinces of Canada and as a national measuring instrument in Australia. [7] In Mexico, one of them with 438 children under 5 years of age from the Federal District ( $\mathrm{n}=152,34.7 \%)$, Yucatán ( $\mathrm{n}=151,34.5 \%)$ and Chihuahua (n $=135,30.8 \%$ ) was validated through different studies ); of 
the total $23 \%$ did not present a risk and the rest with some type of irrigation during the evaluation. [8] This instrument has a sensitivity of 0.81 and a specificity of 0.61 and a lower value was considered as a cut-off point for abnormality in development. 90 in the Total Development Quotient (CTD). [9] In the family medicine unit no. 66 of Xalapa Veracruz, 388 children under 5 years of age were evaluated, of which only $1.3 \%$ had a delay in psychomotor development with a predominance in the area of language and in the social area, without reaching their gestational age and presenting low weight at birth, which suggests that prematurity and low birth weight are determining factors for delaying psychomotor development in this age group. These patients represent a segment of the population attached to the family medicine unit No. 66, practically all of the parents accepted that this test be carried out, having bachelor's and baccalaureate studies with medium-low socio-economic means, The auto tests report are based on the comparison parents make with other children of age and, despite having a normal performance, these children could be more careful, bordering on their psychomotor or social development and that will require subsequent support services [10]. The EDI is a standardized method of support in the evaluation of child development in pediatric outpatient consultation [11]. We think that this undoubtedly is related to an improvement in the quality of care and greater satisfaction of both parents and professionals [12].

\section{Conclusion}

It was demonstrated with a significant sample, the state of development of the child population of the Family Medicine Unit no. 66 using the EDI manual, observing that the majority were in normal parameters of child development only $1.3 \%$ presented developmental lag mainly in the area of language and social, with biological and prenatal risk factors such as gestational age and birth weight. The purpose of this study is to have a psychomotor development validation tool that can be used in the promotion of public and private child health for the timely detection of delayed psychomotor development and can be channeled for care and rehabilitation in a timely manner. In this work there are no conflicts of interest or some type of financing.

\section{References}

1. Rizzoli Córdoba A, O’Shea caves G, Aceves Villagran D, Mares Serratos B, Martel Valdez L, et al. Evaluation of child development in Mexico. The invisible Girls and Boys from 0 to 6 years in Mexico 118-132.

2. López Pisón J, Monge Galindo L (2011) Evaluation and management of children with psychomotor retardation. Generalized developmental disorders, Rev Pediatr Aten Primaria Madrid nov 30(13).

3. Filipa de Castro, Allen-Leigh B, Gregorio Katz MC, Carulla L, LazcanoPonce L (2013) Indicators of child welfare and development in Mexico. Public health Méx Cuernavaca 2(55).

4. Mackrides P, RyherdS (2011) Screening for Developmental Delay. American Academy of Family Physicians 84(5): 544-549.

5. Janus M, Offord D (2007) Development and psychometric properties of the Early Development Instrument (EDI): A measure of children's school readiness. Canadian Journal of Behavioural Science 39: 1-22.

6. Schonhuant L, Salinas P, Armijo R, Schonstedt G, Álvarez J, Manríquez M (2009) Validation of a self-administered questionnaire for the evaluation of psychomotor development. Rev Chil Pediatr 80(6): 513-519.

7. Gollenberg A, Kynch C, Jackson L, McGuinness B, Msall M (2009) Concurrent validity of the parent-completed Ages and Stages Questionnaires, $2^{\text {nd }}$ Ed. With the Bayley Scales of Infant Development II in a low risk simple. Child Care Health Dev 36(4): 485-490.

8. Rizzoli Córdoba A, Schnaas Arrieta L, Liendo Vallejos S, Buenrostro Márquez G, Romo Pardo B, et al. (2013) Validation of an instrument for the timely detection of development problems in 33 children under 5 in Mexico Bol. Med Hosp Infant Mex Mexico 3(70).

9. Rizzoli Córdoba Antonio, Liendo Vallejos Silvia, Romo Pardo Beatriz, Vargas López Guillermo, Pizarro Castellanos, et al. (2013) Complementary Manual for the Application of the Test Evaluation of Child Development "EDI" First Edition. Mexico DF. Ministry of Health, National Commission for Social Protection in Health pp.168.

10. Myers R, Martínez A, Delgado M, Fernández JL, Martínez A, Araujo MC (2013) Early Childhood Development in Mexico, Diagnosis and recommendations. IDB Division of Social Protection and Health.

11. Romo Pardo Beatriz, Liendo Vallejos Silvia, Vargas López Guillermo, Rizzoli Córdoba Antonio, Buenrostro, Márquez Guillermo (2012) Global neurodevelopmental screening tests for children under 5 years of age validated in the United States and Latin America: systematic review and analysis comparative. Med Hosp Infant Mex 69(6): 450-462.

12. Villanueva P Has a developmental delay of $5 \%$ of children, Reforma.
This work is licensed under Creative Commons Attribution 4.0 License

To Submit Your Article Click Here:

Submit Article

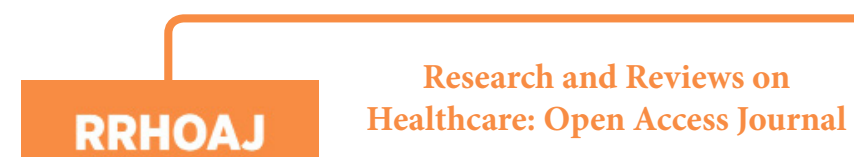

Assets of Publishing with us

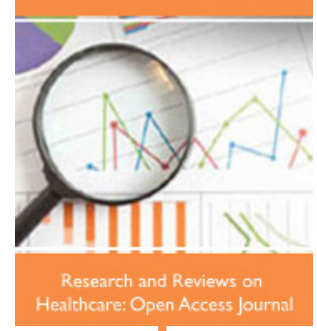

- Global archiving of articles

- Immediate, unrestricted online access

- $\quad$ Rigorous Peer Review Process

- Authors Retain Copyrights

- Unique DOI for all articles 